\title{
Bacterial Meningitis and Deafness in Sub-Saharan Africa
}

\author{
George Wireko-Brobby \\ College of Health Science, School of Medical Sciences, \\ KNUST, Kumasi \\ Ghana
}

\section{Introduction}

Bacterial Meningitis is a leading cause of childhood Deafness in Ghana and the sub- Saharan Africa. Children are predominantly at risk of bacterial meningitis mainly because of their immature immune system, and malnutrition especially in our part of the world. Lack of immunization practices also makes them more susceptible to significantly high morbidity and mortality.

Even with the provision of highly effective antibiotic therapy, death and long-term disabilities are the common but still serious consequences of acute bacterial meningitis in developing countries.

Common neurological complications in both adult and children are motor deficit, cognition deficit, hemiplegia, epilepsy, developmental and learning disabilities, blindness and Deafness.

In this chapter, we shall focus more on the devastating effects of sensorineural Hearing loss or Deafness, after bacterial meningitis. Delay in the Diagnosis of Hearing loss occurs firstly because language development of Hearing impaired children, parallels that of normal infants till the age of nine months. Secondly, because children with profound hearing loss coo and bable until this age, the parents are likely to ignore any subtle evidence of hearing impairment such as lack of response to environmental sound. Damage to the Cochlea, occurs in the early stages of the illness and it is often permanent and irreversible. Woodrow \& Brobby (1997); Daya et al. (1998).

Prevention of deafness relies on early treatment with appropriate antibiotics, but adjunctive treatment with dexametnasore though controversial may be useful in preventing the sequel of sensorineural Hearing loss. In the long term vaccinations may be the most practicable means to reducing the burden of meningitis in the developing countries of Africa.

Facilities for audiological assessment and management of children recovering from meningitis are crucial for the detection of significant hearing impairment and the implementation of rehabilitation programmes. 
Our observation at our University Teaching Hospital (KATH) is that about $20 \%$ of patients who survive with neurological sequelae, permanent sensorineuraal Hearing loss, accounts for approximately $75 \%$ of these cases.

In a study on causes of Deafness in Ghana, Brobby (1998) Meningitis was rated the 3rd amongst other childhood infections. Recent observations predict that meningitis has taken the $2^{\text {nd }}$ position after measles.

This is worrying because even a mild hearing loss of less than $40 \mathrm{Db}$ may have long-term developmental consequences. Given the scale of this problem, there is the need to review critically our knowledge about the natural history of the hearing loss which may follow meningitis and to discuss the applicability of recent therapeutic interventions studied in industrial nations to the diseases in the African contest.

\section{Microbiology}

In Africa, acute bacterial meningitis has an overall annual endemic rate in the region of 1050 per $10^{5}$ populations, a figure at least 10 times that for Europe and the United States, and this disparity appears to be growing. Fortnum (1992). More than 70 per cent of cases are caused by either Streptococcus pneumonia (pneumococcal) or Neisseria meningitides (meningococcal). Haemophius influenza type b $(\mathrm{Hib})$ is responsible for fewer cases in the population as a whole although it is a major problem in children less than 12 months of age, Airede (1993).

Epidemics of meningococcal meningitis sweep through the sub-Saharan 'meningitis belt' every 8 to 12 years. Annual incidence may reach 1 per cent of the population in certain areas.

Although this review concentrates on acute bacterial meningitis in Ghana, tuberculous meningitis is also relatively common in certain areas and is the leading cause of meningitis in the Western Cape Province of South Africa, where deafness. Deafness is a wellrecognized complication. From our experience, viral meningitis has only rarely been associated with deafness.

In Africa seasonal outbreaks and epidemics of meningecal meningitis and septicaemia, numerically represent their greatest public health impact on the continent.

In Ghana, the three polysaccharide encapsulated bacteria for which licensed vaccines are curable are Pneumococcus, Haemophilus influenza type b (Hib) and the Neisseria Menigococcus. Our observation is that Haemophilus influenza type $b$ is responsible for fewer cases of meningitis in our sub-region.

\section{Epidemiology}

A number of factors appear to influence the frequency of post-meningitis hearing loss but it is not possible to predict hearing loss accurately in individual cases. Factors affecting this figure including the causative organism, the pneumococcus causing the highest rate of deafness (31.8 per cent) in comparison with the meningococcus (7.5 per cent) and Hib (11.4 per cent) All ages may develop deafness - the fact that most cases occur in infants may reflect their greater susceptibility to severe infection rather than a particular vulnerability to 
hearing impairment. At a community level, meningitis is one of the most common causes of hearing loss. In Kumasi, Ghana, meningitis is responsible for 8.5 per cent of cases of sensorineural hearing impairment in children.Brobby (1998)

\section{Natural history}

Sensorineural heating loss is typically bilateral, and occurs within 48 hours of the development of meningitis, with the majority of children who go on to suffer permanent damage having abnormal hearing tests on admission to hospital. There appears to be an initial phase of mild, reversible damage. Significant sensorineural hearing loss persisting after the acute phase of the illness is characteristically permanent although cases of partial recovery have been documented on certain occasions. Mild, temporary, conductive deficits are common in the recovery phase. Pathological correlates for these clinical findings are still lacking but potential pathophysiological mechanisms are discussed below.DAYA et al (1997)

\section{Pathology}

The auditory lesion in post-meningitic hearing loss remains obscure. It is likely that more than one mechanism of auditory pathway damage occurs. A body of clinical and experimental evidence suggests that the cochlea is the most frequent site of sensorineural damage, bacteria gaining access to the labyrinth via the cochlear aqueduct. DAYA et al (1998) Cell wall components directly toxic to cochlear hair cells, setting up a serous labyrinthitis In addition, these components also stimulate the inflammatory response, leading to suppurative labyrinthitis and permanent damage; in severe cases the labyrinth may be completely obliterated and neo-ossification occurs. The vestibular apparatus is commonly damaged in conjunction with this process. Other potential mechanisms of deafness include septic thrombophlebitic or embolisation of blood vessels supplying the inner ear and damage to the VIIIth cranial never or central auditory pathways.

\section{Diagnosis}

Screening for deafness during hospitalization is an accurate predictor of hearing impairments at follow-up, and ideally should be performed on all cases. It is also important to examine the middle ear with tympanometry in order to assess conductive impairments, which can be expected to improve with time. A follow-up assessment at approximately 6 weeks, when acute inflammation has subsided, confirms the degree of sensorineural damage and allows appropriate rehabilitation to be instituted. Assessment of hearing loss following meningitis is currently based on audiometric methods. Unfortunately the inaccuracy of age-appropriate tests in healthy children, the infants' lack of consistent response to sound and the effect of associated motor disorders tend to impair the validity of audiometry. More objective methods such as Brainstem Audiometry Evoked Responses (BAERs) and Oto-Acoustic Emissions (OAEs) have yet to reach the clinic in most parts of the continent.

More objective methods such as Brainstean Auditory Evoked responses (BAERs) and OtoAcustic Emulsions (OAEs) are the latest state of the art equipments for this purpose. (DAYA et, al 1998) 
Fortunately, the Kumasi Hearing Assessments Centre established through the magnificent generosity of the Commonwealth Society for the Deaf is the only centre, recognized by the $\mathrm{WHO}$, in Africa, South of the Sahara which has all these facilities.

\section{Acute management}

Prompt Empirical antibiotic treatment should include Agents active agent all main pathogens for the eradication of the infecting organism in order to ensure optimal outcome. The introduction of sulphonamides in the 1950s (primarily for meningococcal meningitis) and of penicillins in the 1960s had a striking effect on incidence of mortality and mobility. The spread of plasmid-borne betalactamases in Hib led to the addition of chloramphenicol to therapy. This combination is still standard in most African countries. The latest challenge to this regimen has been the relatively recent appearance of penicillin-resistant pneumococci and meningococci. Further, some pneumococci are also chloramphenicol-resistant. This will undoubtedly affect the choice of antibiotics although the number of studies documenting a worsening clinical outcome is still small. In Europe and the USA third-generation cephalosporins have become first-line therapy but while these drugs remain relatively expensive, it is probably reasonable for most African hospitals to continue with the combination of a penicillin and chloramphenicol as initial therapy as long as clinicians are aware of the risk of recrudescence, particularly if steroids are being used. Friedland 1998.

A large number of clinical trials have been performed addressing the issue of whether steroids reduce the frequency of adverse outcomes, particularly hearing loss. It is not possible to discuss these studies in detail here, but certain points should be borne in mind when considering the evidence for and against steroids. Most trials could be criticized on methodological grounds because data were analysed without pre-defined end-points, allowing multiple comparisons to be made. In the three trials where significant results have been obtained, there were unusually high incidences of adverse outcome in the placebo group. Furthermore, no study with a consistent antibiotic regimen throughout has shown statistically significant reduction in hearing loss. Despite these problems, the case for giving dexamethasone in Hib meningitis is felt by many authorities to be strong. The role for dexamethasone in pneumococcal and meningococcal disease is at present unresolved.

Many of the trials of both dexamethasone and antibiotic regimens have been performed in the United States, with Hib as the dominant aetiology and so considerable caution should be exercised when applying conclusion to the African setting A recent reported trial in Pakistan found no evidence that dexamethasone was beneficial and suggested that it may be deleterious in this setting. Quazy (1996) Airede (2008)

The finding of different outcomes in various settings is not uncommon. There are clearly huge differences in terms of population, genetics, and timing of presentation, microbiology and general supportive care which can explain this apparent discrepancy. Giving the added cost of dexamethasone to the family of a patient who has already begun receiving two antibiotics, we feel that there is insufficient evidence at this time to recommend routine use of dexamethasone for acute bacterial meningitis of unknown cause. 
Currently, the recommended empirical treatment of meningitis is ampicillin plus an aminoglycoside and a third generation cephalosporin.

The use of dexamethasore remains controversial. But our experience at KATH suggests that initial Doses of 50mg Hydrocartison before the administration of the antibiotics help to reduce the occurance of Sensorineural hearing loss.

\section{Discussion}

The most common causes of bacterial Meningitis in the US, Europe and other developed countries since the 1980s have been the pneumococcus, Haemophilus influenza Type b, the meningococcus, Group B strepotococcus and Listeria monocytogenes.

Works on neonatal meningitis have also shown to involve Strept, agalaciac, Listeria monocytogene, and enteric gram neg. WAS E'coli and citrobacteria spp.Delourois (2009) Longe (1984) Laving (2003).

As already discussed under the epidemiology of meningitis in Africa, the three polysaccharide encapsulated bacteria most common in Ghana and Africa are Pheunococcus, Haemophilus influenza Type B and the Meningococcus.

The global epidemiology changed drastically during the $20^{\text {th }}$ century as vaccines and antibiotics became available to prevent and treat the deadly disease.

Differential Diagonisis of Sensorineural Hearing loss in Ghanaian children revealed that, post-natal infections were the cause of about $60 \%$ of all Sensorineural Hearing loss in Ghanaian children, with measles leading with $30 \%$, followed by malaria (Cerebral) with $14 \%$ and meningitis with $7.5 \%$. See the Table Brobby (I986) ${ }^{11}(1986)^{1}$

Recent observations have revealed that Bacterial meningitis is on the increase threatening to overtake cerebral malaria.

This may be due to better management, and increased awareness and prevention of malaria in the sub region.

It is interesting to note that deafness as a medical and social problem in the third world shows itself not very much differently from the image it portrays itself in the developed countries. However, in the developed countries deafness as a handicap has been made visible and effectively treated and prevented.

For example, all childhood infections like Measles, Meningitis, Mumps and Malaria (the four MS) have been eliminated in the developed countries, by immunization.

The main cause of Deafness in US and Europe is due to otoseclerosis and chromosomal anomalies. For example while as connexin 26 mutation causes only $18 \%$ of Deafness in Ghana; it is responsible for causing $50 \%$ and more of Sensorineural Hearing loss in US and Europe. Brobby (1986) ${ }^{12}(1998)^{13}$ Hammelman et al (2001) 14

It is important to observe that deafness remains a hidden handicap. In Africa delay in diagnosis is common because the vocalization of hearing impaired children parallels that of normal infants until the age of nine months; all children co and bubble; parents are indeed 
likely to assume that speech is developing normally, ignoring any subtle evidence of hearing impatient such as lack of response to environmental sounds.

The effect of deafness on a child is devastating. Ability to participate in school activities or in a community life at a level commensurate with others has been the comparative benchmark for quality of life across the millennia. Participation in the world be it modern or ancient, centres on communication. In ancient Greece, deafness represented a curse, an absence of intelligence, an inability to participate in community life. Throughout mediaval times the inability to understand or express speech meant that an individual was not allowed to inherit the family fortune. Being unable to speak, i.e. to communicate was not allowed to receive the sacraments of the Church, which reflected one of the primary elements of full participation in community life. It is therefore our duty as crusaders for the prevention of deafness to summon all efforts to encourage all Third World Countries to extend their programme of Immunization of the 6 killer diseases which have been eliminated in developed countries, Tuberculosis, Tetanus, Diphtheria, Pertusis, Measles and Poliomyelitis.

The various National Governments should be made aware that Measles, Meningitis, Mumps, Tetanus and Rubellen, can be effectively prevented by cheap, readily available and non-toxic immunization.

\section{Vaccination}

In many industrialized nations Hib has been virtually eliminated by the use of a conjugated vaccine. Before these results can be applied in Africa the epidemiology of Hib disease (uncertain because of technical problems with culture, especially in the face of pretreatment) must be characterized. A recent vaccine trial, in which Hib epidemiology in The Gambia was thoroughly assessed prior to the vaccination campaign, showed 95 per cent efficacy against invasive Hib disease and should serve as a model for future studies. Mulhdlland (1997)

At present, we are unaware of any African country which routinely vaccinates its children against Hib. Clearly, countries have many other health priorities, and the Hib vaccine is still relatively expensive although vaccination may actually be cost-effective in the long-term. Vaccination against group $\mathrm{A}$ and $\mathrm{C}$ meningococcal disease provides relatively short-lived immunity and has so far only been used to abort epidemics. Pneumococcal vaccine development has been hampered by the need to include a large number of serotypes.

\section{Rehabilitation}

Any sensorineural hearing loss is significant since even mild impairments may be of educational significance and subtle high-frequency deficits may interfere with the normal acquisition of language skills. Children with significant losses shuld be enrolled into a programme of rehabilitaition at a hearing assessment centre or a school for the deaf. Parental counselling is crucial for success. Most infants with even profound hearing loss retain some residual function, usually in the low frequencies. With early detection and management, this residual hearing can be harnessed by a comprehensive programme of 
amplification and auditory training (hearing aids and batteries should be commonplace commodities, affordable and available even in developing countries). This approach, in combination with simultaneous use of lip-reading and sign language, can transform the environment of a hearing-impaired child from a world of isolation, confusion and frustration to one of hope.

\section{References}

[1] Woodrow C.J, Brobby, G.W, deafnes, and meningitis in Africa, Postgraduate Doctor. Volume 19, M.4

[2] Daya, H, Woodrow, C.J, Brobby, G.W, et al 1997 pp 89-93, , Assessment of cochlear Damage after pneumococcal Meningitis using otoacustic Emissions. Trans Royal Soc of Tropical medicine and Hygiene $1997 \mathrm{Vol}$ 91, pp 248-249,

[3] Brobby G.W, Causes of congenital and acquired Total Sensorineural Hearing loss in Ghana's children, Tropical Doctor Vol 18, pp30-32, 1988.

[4] Fortnum Hearing impairment after bacterial meningitis; a review Arch dis.cluld 1992 Vol 67, pp128-13, 3.

[5] Airede AI. Neoriatal bacterial meningitis in the middle belt of Nigeria, Developmental Medicine and child Neurology 1993, Vol 35, pp 424-430

[6] Daya, H, Amedofu, G.K. Woodrow, C.J Brobby.G.W. et al Deafness and Meningitis: what can otoacustic Emissions offer, Trans.Royal Soc of Trop.med and Hygiene Proceeding, Aspn Colorado 1997, 1998. pp.10-12,

[7] Fried land IR, klugman K.P. Failure of chloranplricol therapy in peniallure -resistant preumococcal meningitis. Lancet 1992, pp339, 405-408.

[8] Quazi .SA, Khan MA, Mughal etal; dexamethasone and bacterial meningitis in Pakistan Arch Dis chil 1916; Vol 75:pp 482-488

[9] Airede K, Adeyemi O, Ibrahim T, Neonatal bacterial meningitis and dexamethazore adjunctive usage in Nigeria. Nigeria journal of chemical Practice 2008, pp 235245.

[10] Longe C, Omere J, Okoro A, Neonatal meningitis in Nigeria infants Acta padtatrical Scandinarica 1984, Vol 73:pp477-481

[11] Laving AMR, Musoke RN, Wasunna,AO Derathi G. Neonatal bacterial meningitis at the new born unit of Kenyatta national hospital, East Africa medical journal 2003,Vol 80. pp456-462

[12] Brobby G.W, Two cases of otosclciosis in Kumasi Ghana; Case Reports : Tropical and Geographical Medicine 1986 Vol 36 pp.292-295,

[13] Brobby G.W, Muller- Myshok, Horstman R, Connexin 26 R 143 Mutation Associated with Recessive Non-Syudromic Sensorinural Deafness in Africa. New England Journal of Medicine 1998 No 97 pp 3182-3183.

[14] Hammerlman, C, Amedofu, G.K. Brobby G.W. et al Distinct Pattern of Connexin 26 R mutation causing sensorineural Hearing impairment in Ghana. Journal of Human mutation 2000, Vol 9 pp 231-237 
[15] Mulholland K, Hilton S, Adegbila R, et al randomised trial of Hemophilus influenza type-b tetanus/protean conjugate for prevention pneumonia and menigitis in Gambian infants lancet 1997:349(9060) pp 1191-1197. 


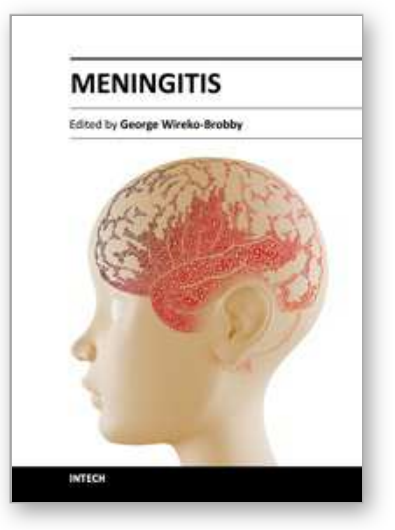

\author{
Meningitis \\ Edited by Prof. George Wireko-Brobby
}

ISBN 978-953-51-0383-7

Hard cover, 232 pages

Publisher InTech

Published online 30, March, 2012

Published in print edition March, 2012

Meningitis is a medical emergency requiring a rapid diagnosis and an immediate transfer to an institution supplied with appropriate antibiotic and supportive measures. This book aims to provide general practitioners, paediatricians, and specialist physicians with an essential text written in an accessible language, and also to highlight the differences in pathogenesis and causative agents of meningitis in the developed and the developing world.

\title{
How to reference
}

In order to correctly reference this scholarly work, feel free to copy and paste the following:

George Wireko-Brobby (2012). Bacterial Meningitis and Deafness in Sub-Saharan Africa, Meningitis, Prof. George Wireko-Brobby (Ed.), ISBN: 978-953-51-0383-7, InTech, Available from: http://www.intechopen.com/books/meningitis/bacterial-meningitis-and-deafness-in-sub-saharan-africa

\section{INTECH}

open science | open minds

\author{
InTech Europe \\ University Campus STeP Ri \\ Slavka Krautzeka 83/A \\ 51000 Rijeka, Croatia \\ Phone: +385 (51) 770447 \\ Fax: +385 (51) 686166 \\ www.intechopen.com
}

\author{
InTech China \\ Unit 405, Office Block, Hotel Equatorial Shanghai \\ No.65, Yan An Road (West), Shanghai, 200040, China \\ 中国上海市延安西路65号上海国际贵都大饭店办公楼405单元 \\ Phone: +86-21-62489820 \\ Fax: $+86-21-62489821$
}


(C) 2012 The Author(s). Licensee IntechOpen. This is an open access article distributed under the terms of the Creative Commons Attribution 3.0 License, which permits unrestricted use, distribution, and reproduction in any medium, provided the original work is properly cited. 